\title{
Achieving more by saying less? On the Moderating Effect of Information Cues in Paid Search
}

\author{
Darius Schlangenotto \\ Paderborn University, Germany \\ Darius.Schlangenotto@upb.de
}

\author{
Dennis Kundisch \\ Paderborn University, Germany \\ Dennis.Kundisch@upb.de
}

\begin{abstract}
Research on ad copy design is well-studied in the context of offline marketing. However, researchers have only recently started to investigate ad copies in the context of paid search, and have not yet explored the potential of information cues to enhance customers' search process. In this paper we analyze the impact of an information cue on user behavior in ad copies. Contrary to prevalent advice, results suggest that reducing the number of words in an ad is not always beneficial. Users act quite differently (and unexpectedly) in response to an information cue depending on their search phrases. In turn, practitioners could leverage the observed moderating effect of an information cue to enhance paid search success. Furthermore, having detected deviating user behavior in terms of clicks and conversions, we provide first indicative evidence of a self-selection mechanism at play when paid search users respond to differently phrased ad copies.
\end{abstract}

\section{Introduction}

In this paper we investigate the question of whether an information cue presented in an ad copy can be used to enhance paid search success. Today, paid search the mechanism of placing online ads in response to user search queries on search engine result pages (SERP) - is already the main source of Internet advertising revenue and expected to grow by $10 \%$ annually over the next four years [1].

As an emerging technology, paid search has spawned numerous new avenues for research, especially in the fields of Information Systems and Marketing [2]. The current literature comprises analytical studies, which focus on the paid search market as a whole, and empirical studies, which address the benefits of paid search for advertisers [3]. In the empirical stream of literature, which is the one we are concerned with here, scholars have mainly focused on the effects of different user search queries (e.g., [4]) and the impact of the visual placement of ads (e.g., [5]) on paid search success. One key aspect of paid search campaigns that has received far less scholarly attention so far has been ad copy design itself [6]. This is surprising as a well-crafted ad is an important success-determinant from an advertiser's perspective [7] to reach the target audience and convince potential buyers to click the ad. Current research has investigated either the use of individual textual elements (e.g., [8]) or message framing (e.g., [9]). Information cues, which marketers commonly use to influence customer behavior by providing additional information, have received a lot of scholarly attention in the field of traditional marketing [1]. However, a study of its benefits is conspicuously absent from the paid search literature. As illustrated with an example in Figure 1, marketers can also vary the amount of information included in a paid search ad copy. Thus advertisers have the option of either presenting a shorter ad which only states the action prompting potential customers to participate in a lottery ("Participate now \& win!") or providing additional text in form of an information cue ("Participate now \& win! Prizes up to $€ 10,000$ "). Appropriate use of such cues would allow advertisers to influence the informationcognition process on the basis of which customers form their perception and behavior [10]. Furthermore, unlike traditional advertising, the unique features of paid search allow advertisers to present differently phrased ads tailored to specific search queries. For example, potential customers searching only for a retailer could be engaged by a shorter ad (see Figure 1, A), whereas a longer ad, incorporating an information cue on the offer, might be suitable for customers explicitly searching for a lottery (see Figure 1, B).

\begin{tabular}{|c|c|c|c|}
\hline Grand Lottery of 'retailer" & \multirow[t]{2}{*}{ A } & Grand Lottery of 'retailer" & \multirow[t]{2}{*}{ B } \\
\hline www.retailer.de/spring & & www.retailer.de/spring & \\
\hline Participate now \& win! & & \multicolumn{2}{|c|}{ porticpate now onym prizes up to $t 10,000$} \\
\hline
\end{tabular}

Figure 1. Ad Copy Design

An empirical study undertaken by Rutz and Trusov on paid search ad copy design [6] suggests that reducing the number of words in an ad copy on average enhances the likelihood of searchers clicking 
on an ad and that therefore a shortened ad copy might be preferable. However, shortened ads restrict the amount of information provided to searchers and therefore pose a challenge to marketers when crafting ad copies. The question arises, then, whether advertisers should try to minimize their descriptions and omit information cues, or whether additional information help persuade searchers to click the ads and thereby increase the chances of triggering a conversion decision. In order to investigate the benefits of including an information cue, and its interrelation to ad length, our study investigates the following research question: How does the inclusion of an information cue in paid search affect user behavior in terms of clicks and conversions?

To answer this question, we teamed up with a wellknown mid-sized business-to-consumer (b2c) furniture retailer operating in Germany. As suggested by Sudhir [11] we made use of the benefits of experimental design and conducted a field experiment via Google using four different ad copies resulting in 280,877 observations. Using logistic regression while controlling for potential confounding factors we reason that an information cue does not necessarily affect user behavior. In fact, a comparison of different search queries reveals that an information cue acts as a moderator in terms of clicks. For example, searchers who include the retailer's name in their query are $10 \%$ more likely to visit the website of an advertiser when an information cue is present in an ad. Users who specifically search for the advertised offer are even more likely to be prompted by an information cue. Providing a cue increases the likelihood of visiting the advertiser's website by $39 \%$. When evaluating searchers' behavior on the website, our results suggest that ads with an information cue only impact the behavior of users who searched for the advertised offer (i.e. the lottery). In these instances, being exposed to an information cue in an ad reduces the likelihood of a website visitor converting (i.e. taking part in a lottery) by $17 \%$. From an advertiser's perspective this behavior is more advantageous since it reduces advertising costs (clicks) by simultaneously increasing conversions. However, from a researcher's perspective this user behavior raises further questions about the motivation and thus opens up new avenues for research.

Our study offers various implications for marketers and researchers. First, our results reveal that ad perception is determined as a function of ad copy design and the search query entered. Consequently, both aspects should be considered jointly when crafting paid search campaigns. Second, the amount of information carried in an ad copy is able to aid customers' search process, and advertisers can make use of the specific information needs of customers to craft ad copies with a length aimed at optimizing their impact. Third, in some instances marketers might leverage deviating user behavior to either maximize the traffic on a website or the number of conversions for a given budget. Finally, our study highlights the need for researchers to evaluate ad copy design on the basis of search queries and to evaluate click and conversion behavior jointly. In addition, research in regard to information cues in the context of paid search should be extended to allow for generalizable statements about the effects of information cues.

\section{Related Literature}

The framing of messages is a well-studied field of research [10] in the context of offline marketing campaigns, in particular the evaluation of information contained in an ad [12]. However, researchers have only just started to investigate different types of messages in the context of paid search. It is already known that user behavior is determined by factors such as the ad copy itself, but also by the search query [13] and the position where the ad appears on a SERP [7]. In order to evaluate user behavior in response to information cues we shall consider three areas of paid search research: keywords, ad positioning, and ad copies. In paid search user behavior is commonly evaluated on the basis of click-through-rates (CTR) and conversion-rates (CVR). CTR is defined as the percentage of users clicking on the ad out of the total number of users who were exposed to it (impressions). In some cases marketers aim to coax users to engage in a specific action (conversion) after clicking the ad. CVR is defined as the number of users who carry out a desired action out of the total number of people who clicked the ad.

In the context of paid search advertisers have to define keywords for which they want to be listed on the SERP. Whenever a user enters search terms into a search engine, this will be linked to contextually matching keywords and display ads of marketers who bought those keywords. Rutz and Bucklin [14] arrange search-phrases by distinguishing between generic terms (e.g., "furniture") and more specific branded terms (e.g., "furniture of retailer X"). Having found evidence for spillover effects from generic to branded queries, they conclude that there are systematic differences between search engine user characteristics, in terms of the wording of the query. For example, if a user incorporates the brand name of the company in their search it is obvious that they are already familiar with the brand and may have formed specific associations towards the brand and/or its products. This user heterogeneity in relation to keyword 
characteristics is supported by Nottorf and Funk [15] and Lu and Zhao [4] who empirically show that users act differently in terms of CTR and CVR relative to the keyword characteristics entered. Jansen et al. [13] particularly focus on the interrelation between keywords and the ad copy. Their analysis reveals that brand keywords in combination with a branded ad copy design is a major driver of sales revenue. Their results indicate that, based on the entered keywords, searchers might show a distinct behavior in response to differently phrased ad copies. Conceptually speaking, the current body of knowledge suggests that keyword characteristics might be a pivotal determinant of user behavior and need to be considered when analyzing ad copy design effects.

A multitude of ads might be presented to the user on a SERP. The number of ads shown depends on how many advertisers have bought keywords matching the search query. Google Search, for example, presents up to four ads in the most prominent slots directly below the search query. In addition, up to three other ads might be placed at the end of the SERP. Current research suggests that CTRs (e.g., [16], [17]) as well as CVRs (e.g., [5], [6]) are highly influenced by the visual placement of the ad on a SERP. Yet, at least in terms of CTR, position effects seem to be weaker for smaller firms and more specific search queries [17]. A field experiment conducted by Animesh et al. [7] studies the relationship between ad copy designs and different ad positions. The authors conclude that crafting an ad with a unique selling proposition is not sufficient to affect click behavior, whereas an ad copy that differentiates the firm from others is moderated by its visual placement on a SERP. The researchers argue that different types of customers are likely to click on the ad depending upon its position, and therefore, the ad position parameter lends itself to segmenting customers into groups. The idea of customer segmentation based on ad positions is also adopted by Rutz and Trusov [6], who suggest that advertisers should change the offer presented in an ad copy depending upon its position on a SERP. Conceptually speaking, the current body of knowledge suggests that searchers who reach an advertiser's website via a toppositioned ad might act differently compared to users who reached the website via an ad which was placed lower down at the end of the SERP.

With regard to ad copy design, researchers have focused either on individual phrasing elements or on the ad copy as a whole. Assessing individual phrasing elements, Turnbull and Bright [18] conclude that ad copies should not incorporate questions in the title. Their analysis of different paid search campaigns reveals that a question in the ad reduces CTR significantly compared with a statement-based phrasing. Atkinson et al. [8] focus on a multitude of individual textual elements used in paid search campaigns of an automotive retailer in Australia. Performing a correlational analysis they conclude that users behave significantly differently in terms of CTR in response to the placement of various ad copy elements. Results suggest that user behavior is affected by various textual elements such as brand names and call-to-actions, but might differ in respect to their placement within an ad copy. In a field experiment in cooperation with a b2c retailer in the Netherlands, Haans et al. [19] investigate the influence of different description texts in an ad copy. Amongst other aspects the scholars investigate the effectiveness of alternative descriptions in terms of conversions and report that for the tested description types the CTR is not suited as an approximation of CVR. An effect description, for instance, is associated with the lowest CTR but leads to the highest CVR. Assessing ad copy designs as a whole Yoo [20] performed an experiment in order to shed light on the question of how messages should be framed in the context of paid search in order to enhance clicks. The study differentiates messages in terms of a customer's low or high level of involvement which is indicative of the degree of interest they have in a product category or brand. They find that a positive framing of ad proposals increases CTR in the context of low-involvement products or brands by $25 \%$ compared to a negative framing. For high-involvement products or brands a negative framing is more effective compared to a positive one, and increases CTR by 20\%. Rutz and Trusov [6] implement a two-stage consumer model to assess paid search ads placed by the mobile ringtone industry. Evaluating ad copy design the authors conclude that a low ad density is generally favorable. Removing just one word from the title increases CTR by $2 \%$, whilst reducing the description by one word increases CTR by $4 \%$. Yet, results are limited to users' click behavior and do not distinguish between content and framing differences as such, which are known to impact user behavior as well.

The current state of the literature does assess individual text elements as well as message framing as such, but completely lacks research on the potential benefits of incorporating an information cue, despite the fact that, at least in the context of offline marketing campaigns, it is known to affect user behavior [12]. Therefore, we would like to augment current research by analyzing the impact of an information cue upon online user behavior. Previous studies have stressed the need to incorporate keyword characteristics as well as the ad positioning when analyzing ad copy design. Thus, we assess the effect of information cues in respect of keyword characteristics while controlling for possible ad position effects. 


\section{Hypothesis Development}

Research suggests that keywords characteristics can be seen as a proxy which encapsulates different information needs of searchers [14]. Consequently, we expect search engine users to consider an information cue either as useful or as unnecessary. We make use of established keyword groupings to formulate our hypotheses. To prevent biases every keyword is assigned to a mutually exclusive keyword cluster and no complex keyword combinations (such as "buy BILLY at IKEA") which could be possibly assigned to a multitude of clusters are used. In accordance to Haans et al. [19], we consider user behavior in terms of clicks as well as conversions, given that ad copy design might affect both.

In line with the current state of the literature (e.g., [4], [14]) a keyword cluster is established which is comprised of generic, unspecific keywords (e.g., "furniture"). We expect searchers' behavior not to be influenced at all when an information cue presented for a specific offer is unrelated to their generic search query. Hence, we have our first set of hypotheses:

H1a: For paid search ads prompted by searches based on generic keywords, an information cue does not affect an individual's likelihood to click on the ad.

H1b: For paid search ads prompted by searches based on generic keywords, an information cue does not affect an individual's likelihood to convert.

As suggested by Ghose and Yang [21] more specific search queries should be divided further into retailer and product-specific keywords to capture individual search intentions. Hence, a retailer-specific cluster is established which is comprised of keywords that include the name of the retailer with whom we executed the experiment. If searchers incorporate the retailer name into their query, it is obvious that they are already familiar with the brand and might have formed specific associations towards the brand and/or its' products. Results of a recent field experiment by Blake et al. [22] suggest that, at least for well-known brands, search queries including the retailer name are primarily used by searchers as a navigational shortcut to the retailers' website. The scholars argue that retailerspecific keywords do not seem to influence search behavior at all. As our partner firm is also a wellknown brand we also expect no information cue effect: H2a: For paid search ads prompted by searches based on retailer-specific keywords, an information cue does not affect an individual's likelihood to click on the ad.

H2b: For paid search ads prompted by searches based on retailer-specific keywords, an information cue does not affect an individual's likelihood to convert.

A third cluster is comprised of product-specific keywords. In our research environment an online- lottery is advertised. In turn, all users searching for a lottery are attributed to product-specific keywords. In line with Jansen et al. [13] we expect for those keywords an information cue to provide useful information in regard to the specific offer. Therefore, searchers should be more likely to click on ads which contain an information cue. In addition, an information cue allows searchers to evaluate the details of the offer before visiting the website. Those searchers who take the time to read a lengthier ad copy might even be more interested in the offer and should in turn be more likely to convert.

H3a: For paid search ads prompted by searches based on product-specific keywords, an information cue increases an individual's likelihood to click on the ad.

H3b: For paid search ads prompted by searches based on product-specific keywords, an information cue increases an individual's likelihood to convert.

\section{Methodology}

We teamed up with a well-known b2c bricks-andmortar furniture retailer in Germany in order to estimate the impact of an information cue on user behavior. In cooperation with the chain, which has requested to remain anonymous, we crafted a paid search campaign. The specific conversion goal of our campaign was to turn paid search website visitors into lottery participants. To test for the information cue effect while simultaneously accounting for the fact that the ad copy length might also influence behavior [6] four different ad copies were crafted (see Table 1). Two ad copies contained no information cue and just focused on the offer to motivate user actions. Ad_s is associated with the lowest ad length and provides a shortened call-to-action. Ad_1 is associated with an increased ad length by providing an extended version of the call-to-action. The two remaining ad copies contained an information cue. We made use of the well-established procedure developed by Resnik and Stern [23] to craft our own information cue ("Prizes up to $€ 10,000)$. The cue provides information in regard to the conversion goal by stating the prize that searchers can win when participating in the lottery. Ad_s-i incorporates the shortened call-to-action (as used in Ad_s) in combination with the defined information cue and Ad_1-i incorporates the extended version of the call-to-action (as used in Ad_1) in combination with the defined information cue. Using different ad lengths allows us to isolate the information cue effect. When searchers are affected by the information cue as such, the effect should be consistent throughout all ad copy variants. 
Table 1. Tested ad copies

\begin{tabular}{|c|c|c|c|}
\hline Ad Copies & & $\begin{array}{c}\text { Ad } \\
\text { Length }^{1}\end{array}$ & $\begin{array}{r}\text { Info } \\
\text { cue } \\
\end{array}$ \\
\hline Grand Lottery of 'retailer' & Ad_s & \multirow{3}{*}{55} & \multirow{3}{*}{ No } \\
\hline www.retailer.de/spring & & & \\
\hline \multicolumn{2}{|c|}{ Participate now? } & & \\
\hline Grand Lottery of 'retailer' & Ad_l & \multirow{3}{*}{66} & \multirow{3}{*}{ No } \\
\hline www.retailer.de/spring & & & \\
\hline \multicolumn{2}{|c|}{ Participate now \& wint } & & \\
\hline Grand Lottery of 'retailer' & Ad_s-i & \multirow{3}{*}{91} & \multirow{3}{*}{ Yes } \\
\hline www.retailer.de/spring & & & \\
\hline \multicolumn{2}{|c|}{ Participate now prizes up to 10000} & & \\
\hline Grand Lottery of 'retailer' & Ad_l-i & \multirow{3}{*}{102} & \multirow{3}{*}{ Yes } \\
\hline www.retailer.de/spring & & & \\
\hline \multicolumn{2}{|c|}{ 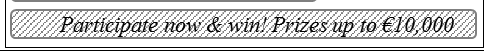 } & & \\
\hline $\begin{array}{r}\text { Ad copies } \\
\text { measured as } t\end{array}$ & slated & German to & $\begin{array}{l}\text { glish. } \\
\text { arch }\end{array}$ \\
\hline
\end{tabular}

As suggested by Bandiera et al. [24] we designed a well-controlled field experiment using Google AdWords A/B testing mechanism. For 62 days users searching for furniture and lottery related phrases within the advertising reach of the b2c chain were equally likely to be randomly exposed to one of the four different ad copies. To prevent biases, the websites on which the lottery was offered were not changed during experiment execution. Current findings on effective ad copy design were incorporated in all ad variants that were tested to prevent potentially confounding effects driven by improper ad contents. According to Yoo [20] we positively framed the general ad copy text. Based on Atkinson et al. [8] the title contained a value puffery and named the retailer brand. Following Rutz and Trusov [6] every description text contained attention grabbing content by incorporating a call-to-action (see Table 1). The position on which an ad is displayed is considered to be one of the main success determinants of paid search campaigns (e.g., [5], [16]) and user characteristics might be significantly different from each other based on the ad position [7]. To prevent confounds we aimed to build a homogeneous sample by executing a paid search campaign which targeted the most prominent ad positions directly below the search query (slots 1-4). To ensure proper placements of ads directly below the search query we used maximum bid values above market average throughout the experiment. However, due to the dynamic bidding process in paid search, in some instances ads were being placed in less prominent positions at the end of the SERP. We control for these effects by distinguishing between top positioned ads (Pos_t $)$ as well as ads which were placed at the bottom (Pos_b).
Searchers' behavior in response to an information cue is analyzed in respect of the two dichotomously distributed variables: clicks and conversions. When exposed to an ad a user has two distinct options, either clicking the ad (click $=1)$ or refusing to click (click = 0 ). When a user clicked the ad s/he will be exposed to the website which offers the opportunity to participate in the lottery (i.e., the conversion goal). Again, the user has two distinct options, either participating in the lottery (conversion $=1$ ) or refusing to take part (conversion $=0$ ). Accordingly, to test for the effect of ad copy design and its interrelation to keywords while accounting for possible positioning effects on the binary outcome variables we use multiple binary logistic regression. By doing so it is possible to distinguish between effects that are driven by the ad copy, effects which are caused by keyword characteristics, and moderating effects which are based on interrelations between ad copy design and keyword characteristics. Thus, we consider the following model in latent variable form [25] as our main model:

$Y^{*}=\beta_{0}+\beta_{1} A d_{i}+\beta_{2} K w_{j}+\beta_{3} \operatorname{Pos}_{k}+\beta_{4}\left(A d_{i} * K w_{j}\right)+\varepsilon$, $Y=1\left[Y^{*}>0\right]$.

where $\mathrm{Y}$ equals one when a user either clicked the ad or converted (in cases where conversion is used as dependent variable). $\mathrm{Ad}_{\mathrm{i}}$ is coded as the independent ad copy designs i (Ad_s. Ad_l, Ad_s$\left.\mathrm{i}, \mathrm{Ad} \_1-\mathrm{i}\right) . \mathrm{Kw}_{\mathrm{j}}$ distinguishes between generic keywords (Kw_g), retailer-specific keywords (Kw_s-r) and product-specific keywords (Kw_sc). $\operatorname{Pos}_{k}$ accounts for top-positioned (Pos_t ) and ads that are placed at the end of a SERP (Pos_b). Variable $\varepsilon$ captures the random error term. Figure 2 depicts our analysis framework and its interrelation to our hypotheses. Based on Davis' [26] suggestions, dummy coding is used as we compare group differences of various ad copies.

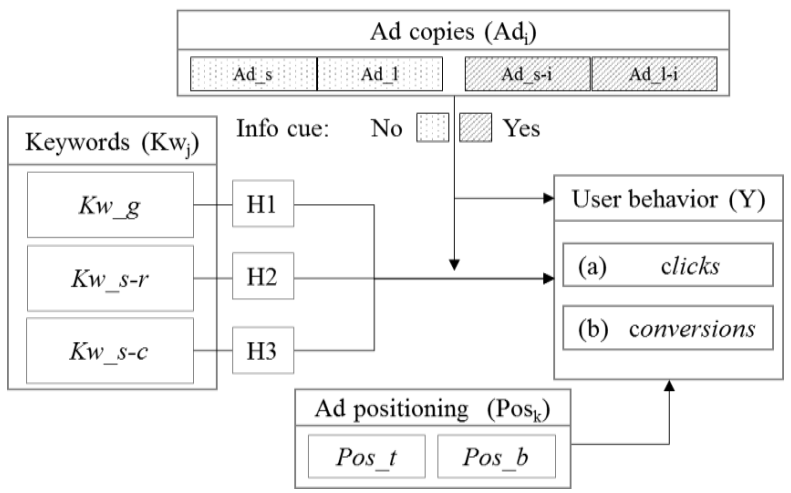

Figure 2. Analysis Framework 


\section{Empirical Analysis}

Throughout the 62 days' experimental period the four different ad copies were presented 280,877 times in response to search queries. 12,487 searchers clicked on the ads and 2,728 showed a conversion by taking part in the advertised lottery. As can be seen in Figure 3 searchers act differently based on keyword characteristics (generic, retailer-specific, productspecific). In regard to ad copy design, CTR values indicate that retailer, as well product-specific searchers, might be positively affected by an information cue. CVR values indicate that the conversion likelihood depends on keyword characteristics, but users might only be affected by an information cue when searching for product-specific keywords. Performance metrics generally indicate a well-performing marketing campaign. The percentage of searchers who clicked on an ad (CTR) ranges from $1.4 \%$ for generic-search request to $11.1 \%$ for retailerspecific keywords. The percentage of customers who convert when they have reached the website (CVR) ranges from $6.7 \%$ for generic keywords to $34.9 \%$ for product-specific keywords. To answer our research question, we devised hypotheses sets for each keyword group so they can be analyzed individually. ${ }^{1}$

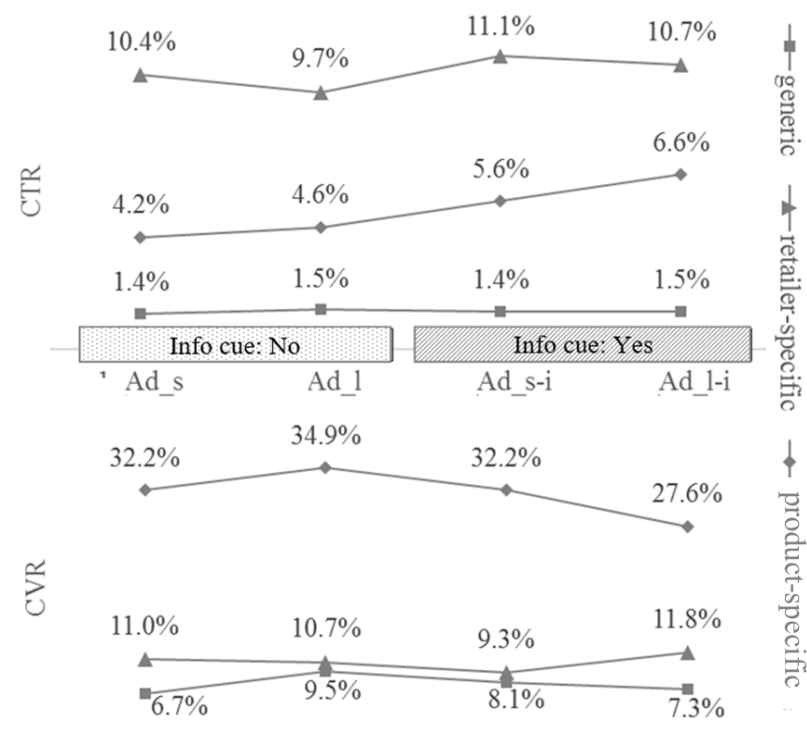

Figure 3. Click and conversion behavior

\footnotetext{
${ }^{1}$ Extended variants of all regression analyses, control variables and additional main effect analyses including further information are provided as an online resource: http://go.upb.de/AdCopyDesign
}

\subsection{Generic keywords}

Logit results using clicks as the dependent variable indicate that searchers using a generic keyword do not seem to be affected by an information cue (see Table 3, generic). Assessing group differences between the four distinct ad copies yields insignificant log-odds effects which are close to zero. As expected, searchers using unspecific keywords do not seem to have been affected by an information cue which highlights a specific conversion goal and therefore hypothesis H1a is accepted. However, interaction terms suggest that searchers using retailer-specific (Kw_s-r) as well as those who use product-specific terms (Kw_s-c) are affected significantly differently by an information cue contained in the ad copies (Ad_s-i, Ad_s-1). Logit regression using conversions as the dependent variable also yields insignificant results (see Table 4, Generic). As expected, searchers who reached the website via a generic search phrase are not influenced by an information cue that highlights specific benefits of the conversion and therefore hypothesis H1b is accepted. Summing up, the behavior of searchers who used generic search terms cannot be influenced by incorporating an information cue. In addition, ad length does not seem to impact user behavior at all.

\subsection{Retailer-specific keywords}

For retailer-specific keywords, our results suggest that an information cue does increase the likelihood of a searcher clicking on an ad (see Table 3, retailerspecific). Ad copies which include an information cue (Ad_s-i, Ad_l-i) are associated with significantly positive log-odds. However, effects are negligible when comparing ads which do not contain an information cue (Ad_l, Ad_s). Contrary to the findings of Blake et al. [22] our results reveal that at least a percentage of users does not use paid ads as a navigational shortcut as we observe a significant information cue effect on clicks. Thus, hypothesis H2a is rejected as searchers respond significantly positive to an information cue. Interaction terms suggest that these searchers are affected differently in terms of clicks compared to all other keyword groups in response to the tested ad copies. When using conversions as the dependent variable (see Table 4, retailer-specific) logit regression results remain insignificant. As expected, on a conversion level, searchers who reached the website via a retailer-specific keyword do not seem to be influenced by an information cue and therefore hypothesis $\mathrm{H} 2 \mathrm{~b}$ is accepted. Summing up, searchers who are known to be familiar with the retailer, on account of having entered a retailer-specific keyword, 
are positively influenced by an information cue. Accordingly, providing additional information can be utilized to increase the percentage of website visitors who are already familiar with the retailer.

\subsection{Product-specific keywords}

For product-specific search terms compared to the base case (Ad_l) all ad copies impact click behavior (see Table 3, product-specific). Both ad copies incorporating the information cue (Ad_s-i, Ad-1-i) are associated with a positive and highly significant $(\mathrm{p}<0.01)$ log-odds effect. Comparing ad copies that do not incorporate the information cue reveals a significant negative impact of a shortened ad copy design (Ad_s) on click performance. For productspecific searches, ad length as well as the use of information cues influence the click behavior of searchers. Even when significant differences in ad length' are detected, providing a specific information cue enhances the likelihood of searchers clicking on an ad. Therefore, hypothesis $\mathrm{H} 3 \mathrm{a}$ is accepted. When assessing conversion effects, an opposite effect is observed (see Table 4, product-specific). This means that an information cue (Ad-s-i, Ad-1-i) significantly reduces the likelihood of searchers to take part in the advertised lottery. As the information cue provides additional information on the lottery we would have expected to observe an increased likelihood of searchers participating in it. Log-odds suggest an opposite effect and therefore hypothesis $\mathrm{H} 3 \mathrm{~b}$ is rejected. Such a diametric user behavior in terms of clicks and conversions is also observed by Haans et al. [19] and might be seen as another indication for a selfselection mechanism in the context of paid search [13]. Interaction terms reveal that users who search for product-specific terms respond significantly different in terms of clicks compared to all other keyword groups. Comparing interaction effects for retailerspecific keywords also yield heterogonous treatment effects between retailer-specific and product-specific keywords (see Table 3, Ad_s:Kw_s-r and Ad_1$\left.\mathrm{i}: \mathrm{Kw} \_s-r\right)$. Summing up, for product-specific keywords empirical results reveal a diametric user behavior. In the data set searchers who specifically search for an offer are more likely to click on an ad when additional information in regard to the offer is provided. Yet, when these searchers reach the website their behavior changes. Logit regressions suggest that searchers who searched for the specific conversion goal, and who would decide whether to visit a website on the basis of additional information in regard to the offer, are far less likely to convert.

\section{Economic significance of results}

To evaluate the impact of the information cue as such, ad copies are pooled with respect to their information degree. ${ }^{2}$ Ads that do not contain the information cue (Ad_s, Ad_1) are compared to those that do (Ad_s-i, Ad-l-i). Table 5 depicts logit results for the pooled ad copies for those keyword groups which yield significant effects in terms of clicks and/or conversions. The variable Info estimates the information cue effect on the dependent variable. As logistic regression analyses are used, coefficients cannot be interpreted as the direct impact on a change in the output variable for a one-unit increase in the respective predictor variable, while all other predictors remain constant. Instead, odds-ratios need to be used [27]. As can be seen in Table 5, when retailer-specific keywords provide additional information, clicks are significantly enhanced. The odds-ratio indicate that searchers who use a retailer-specific phrase are $10 \%$ (Confidence Interval: $2.5 \%=1.03 ; 97.5 \%=1.16$ ) more likely to click on an ad which contains an information cue. In comparison to generic (Info:Kw_g) and product-specific (Info:Kw_s-c) keywords, users searching for retailer-specific keywords respond significantly differently on additional information. For product-specific keywords the odds-ratio suggest that searchers are $39 \%$ (Confidence Interval: $2.5 \%=1.34$; $97.5 \%=1.44$ ) more likely to click on an ad which provides an information cue. In addition, the highly significant difference in the interaction term (See Table 5, Info:Kw_s-r) suggests that providing additional information for product-specific search terms affects clicks over proportionately compared to retailerspecific keywords. Yet, on a conversion level, users who searched for product-specific keywords are significantly less likely to convert when they were exposed to an information cue. The odds-ratio suggests that searchers who used product-specific phrases and were exposed to an information cue, were subsequently $17 \%$ (Confidence Interval: $2.5 \%=0.73 ; 97.5 \%=0.94$ ) less likely to take part in the advertised lottery.

\footnotetext{
${ }^{2}$ Based on the obtained results (See Table 3, 4) pooling of ad copies is a valid procedure as all ads which will be grouped together affect the dependent variable either positively or negatively.
} 
Table 3. Logit model Dependent variable: Clicks

\begin{tabular}{|c|c|c|c|c|c|c|c|}
\hline Model & generic & $\begin{array}{l}\text { retailer- } \\
\text { specific }\end{array}$ & $\begin{array}{l}\text { product- } \\
\text { specific }\end{array}$ & Model & generic & $\begin{array}{l}\text { retailer- } \\
\text { specific }\end{array}$ & $\begin{array}{l}\text { product- } \\
\text { specific }\end{array}$ \\
\hline Ad_s & $\begin{array}{l}-0.10 \\
(0.07)\end{array}$ & $\begin{array}{c}0.07 \\
(0.05)\end{array}$ & $\begin{array}{c}-0.08^{* *} \\
(0.04)\end{array}$ & Ad_s & $\begin{array}{l}-0.38 \\
(0.28)\end{array}$ & $\begin{array}{c}0.03 \\
(0.15)\end{array}$ & $\begin{array}{l}-0.12 \\
(0.08)\end{array}$ \\
\hline Ad_s-i & $\begin{array}{l}-0.08 \\
(0.07)\end{array}$ & $\begin{array}{l}0.14^{* * *} \\
(0.05)\end{array}$ & $\begin{array}{l}0.20^{* * *} \\
(0.04)\end{array}$ & Ad_s-i & $\begin{array}{l}-0.18 \\
(0.24)\end{array}$ & $\begin{array}{l}-0.15 \\
(0.15)\end{array}$ & $\begin{array}{l}-0.12^{*} \\
(0.07)\end{array}$ \\
\hline Ad_l-i & $\begin{array}{l}-0.04 \\
(0.07)\end{array}$ & $\begin{array}{l}0.11^{* *} \\
(0.05)\end{array}$ & $\begin{array}{l}0.37^{\text {*** }} \\
(0.03)\end{array}$ & Ad_l-i & $\begin{array}{l}-0.30 \\
(0.25)\end{array}$ & $\begin{array}{c}0.11 \\
(0.15)\end{array}$ & $\begin{array}{c}-0.34^{* * *} \\
(0.07)\end{array}$ \\
\hline Ad_s:Kw_s-r & $\begin{array}{l}0.17^{*} \\
(0.09)\end{array}$ & & $\begin{array}{l}0.15^{* *} \\
(0.06)\end{array}$ & Ad_s:Kw_s-r & $\begin{array}{c}0.42 \\
(0.31)\end{array}$ & & $\begin{array}{c}0.16 \\
(0.17)\end{array}$ \\
\hline Ad_s-i:Kw_s-r & $\begin{array}{c}0.23^{* * *} \\
(0.08)\end{array}$ & & $\begin{array}{l}-0.05 \\
(0.06)\end{array}$ & Ad_s-i:Kw_s-r & $\begin{array}{c}0.03 \\
(0.29)\end{array}$ & & $\begin{array}{l}-0.02 \\
(0.17)\end{array}$ \\
\hline Ad_1-i:Kw_s-r & $\begin{array}{l}0.15^{*} \\
(0.09)\end{array}$ & & $\begin{array}{c}-0.26^{* * *} \\
(0.06)\end{array}$ & Ad_1-i:Kw_s-r & $\begin{array}{c}0.41 \\
(0.29)\end{array}$ & & $\begin{array}{c}0.46^{* * *} \\
(0.16)\end{array}$ \\
\hline Ad_s:Kw_g & & $\begin{array}{l}-0.17^{*} \\
(0.09)\end{array}$ & $\begin{array}{l}-0.01 \\
(0.08)\end{array}$ & Ad_s:Kw_g & & $\begin{array}{l}-0.42 \\
(0.31)\end{array}$ & $\begin{array}{l}-0.26 \\
(0.29)\end{array}$ \\
\hline Ad_s-i:Kw_g & & $\begin{array}{c}-0.23^{* * *} \\
(0.08)\end{array}$ & $\begin{array}{c}-0.28^{* * *} \\
(0.08)\end{array}$ & Ad_s-i:Kw_g & & $\begin{array}{l}-0.03 \\
(0.29)\end{array}$ & $\begin{array}{l}-0.05 \\
(0.25)\end{array}$ \\
\hline Ad_l-i:Kw_g & & $\begin{array}{l}-0.15^{*} \\
(0.09)\end{array}$ & $\begin{array}{c}-0.41^{* * *} \\
(0.08)\end{array}$ & Ad_l-i:Kw_g & & $\begin{array}{l}-0.41 \\
(0.29)\end{array}$ & $\begin{array}{c}0.05 \\
(0.26)\end{array}$ \\
\hline Ad_s:Kw_s-c & $\begin{array}{c}0.01 \\
(0.08)\end{array}$ & $\begin{array}{c}-0.15^{* *} \\
(0.06)\end{array}$ & & Ad_s:Kw_s-c & $\begin{array}{c}0.26 \\
(0.29)\end{array}$ & $\begin{array}{l}-0.16 \\
(0.17)\end{array}$ & \\
\hline Ad_s-i:Kw_s-c & $\begin{array}{l}0.28^{* * *} \\
(0.08)\end{array}$ & $\begin{array}{c}0.05 \\
(0.06)\end{array}$ & & Ad_s-i:Kw_s-c & $\begin{array}{c}0.05 \\
(0.25)\end{array}$ & $\begin{array}{c}0.02 \\
(0.17)\end{array}$ & \\
\hline Ad_1-i:Kw_s-c & $\begin{array}{l}0.41^{* * *} \\
(0.08)\end{array}$ & $\begin{array}{l}0.26^{* * *} \\
(0.06)\end{array}$ & & Ad_1-i:Kw_s-c & $\begin{array}{l}-0.05 \\
(0.26)\end{array}$ & $\begin{array}{c}-0.46^{* * *} \\
(0.16)\end{array}$ & \\
\hline Controls $^{1}$ & $\checkmark$ & $\checkmark$ & $\checkmark$ & Controls ${ }^{1}$ & $\checkmark$ & $\checkmark$ & $\checkmark$ \\
\hline Constant & $\begin{array}{c}-3.62^{* * *} \\
(0.05)\end{array}$ & $\begin{array}{c}-2.22^{* * *} \\
(0.04)\end{array}$ & $\begin{array}{c}-2.81^{* * *} \\
(0.03)\end{array}$ & Constant & $\begin{array}{c}-2.27^{* * *} \\
(0.17)\end{array}$ & $\begin{array}{c}-2.13^{* * *} \\
(0.11)\end{array}$ & $\begin{array}{c}-0.63^{* * *} \\
(0.05)\end{array}$ \\
\hline Observations & 280,877 & 280,877 & 280,877 & Observations & 12,487 & 12,487 & 12,487 \\
\hline Log Likelihood & $-46,539$ & $-46,539$ & $-46,539$ & Log Likelihood & $-6,091$ & $-6,091$ & $-6,091$ \\
\hline Akaike Crit. & 93,105 & 93,105 & 93,105 & Akaike Crit. & 12,208 & 12,208 & 12,208 \\
\hline Notes: & \multicolumn{3}{|c|}{$\begin{array}{l}{ }^{1} K w_{-} s-r, K w \_g, K w \_s-c, P o s \_b ; \\
\text { Standard errors in parentheses; } \\
\text { Ad_l, Pos_t used as base cases; } \\
\quad{ }^{*} p<0.1 ;{ }^{* *} p<0.05 ;{ }^{* * *} p<0.01\end{array}$} & Notes: & \multicolumn{3}{|c|}{$\begin{array}{l}{ }^{1} K w_{-} s-r, K w \_g, K w_{-} s-c, P o s \_b ; \\
\text { Standard errors in parentheses; } \\
\text { Ad_l, Pos_t used as base cases; } \\
\quad{ }^{*} p<0.1 ;{ }^{* *} p<0.05 ;{ }^{* * *} p<0.01\end{array}$} \\
\hline
\end{tabular}
Table 4. Logit model -
Dependent variable: Conversions 
Table 5. Logit model - Information effects

\begin{tabular}{|c|c|c|c|}
\hline Model & $\begin{array}{l}\text { retailer- } \\
\text { specific }\end{array}$ & $\begin{array}{l}\text { product- } \\
\text { Specific }\end{array}$ & $\begin{array}{l}\text { product- } \\
\text { Specific }\end{array}$ \\
\hline Dep. Variable & Clicks & Clicks & Conversions \\
\hline$\overline{\text { Info }}$ & $\begin{array}{l}0.09^{* * * *} \\
(0.03)\end{array}$ & $\begin{array}{l}0.33^{* * * *} \\
(0.03)\end{array}$ & $\begin{array}{c}-0.18^{* * * *} \\
(0.05)\end{array}$ \\
\hline Info:Kw_s-r & & $\begin{array}{c}-0.24^{* * *} \\
(0.04)\end{array}$ & $\begin{array}{c}0.15 \\
(0.12)\end{array}$ \\
\hline Info:Kw_g & $\begin{array}{l}-0.10^{*} \\
(0.06)\end{array}$ & $\begin{array}{c}-0.34^{* * *} \\
(0.06)\end{array}$ & $\begin{array}{c}0.11 \\
(0.19)\end{array}$ \\
\hline Info:Kw_s-c & $\begin{array}{c}0.24^{* * * *} \\
(0.04)\end{array}$ & & \\
\hline Controls $^{1}$ & $\checkmark$ & $\checkmark$ & $\checkmark$ \\
\hline Constant & $\begin{array}{c}-2.18^{* * *} \\
(0.02)\end{array}$ & $\begin{array}{c}-2.85^{* * *} \\
(0.02)\end{array}$ & $\begin{array}{c}-0.69^{* * *} \\
(0.04)\end{array}$ \\
\hline Observations & 280,877 & 280,877 & 12,487 \\
\hline $\begin{array}{l}\text { Log } \\
\text { Likelihood }\end{array}$ & $-46,559$ & $-46,559$ & $-6,100$ \\
\hline Akaike Crit. & 93,1331 & 93,133 & 12,214 \\
\hline Notes: & & $\begin{array}{l}\text { Kw_g } \\
\text { derrol }\end{array}$ & $\begin{array}{l}v_{-} s-c, \text { Pos_b; } \\
\text { parentheses; } \\
05 ;{ }^{* * * *} p<0.01\end{array}$ \\
\hline
\end{tabular}

\section{Discussion}

The reported field experiment was conducted to investigate the question of whether an information cue affects user behavior. Our empirical analysis provides evidence that in respect to the entered search phrase users might be affected differently. In our case, at least, information cues only affect searchers who use specific search terms, such as including the name of the advertising retailer in their query. In this case the users are $10 \%$ more likely to click on an ad which makes use of an information cue that highlights the benefits of a specific offer, which may not necessarily be related to their search intent. Web users who specifically search for the advertised offer are also positively affected by an information cue and are 39\% more likely to click on an ad which provides additional information. In such cases an information cue also affects the conversion likelihood. Users who specifically search for the advertised offer and click on an ad that provides an information cue are $17 \%$ less likely to convert. In other words, for product-specific keywords, users show contradictory conversion behavior in response to an information cue. Thus, we are able to refine the findings of Haans et al. [19] who also conclude that searchers might show deviating behavior in terms of clicks and conversions in response to differently phrased ad copies. Our study suggests that deviating behavior in response to ad copies is indeed present, but appears to be limited to web users with particular types of search intentions.

Our results have several practical implications. The experiment suggests that an information cue is a strong predictor of user behavior and can be effectively leveraged by marketers to enhance paid search success. However, our in-depth analysis of different types of ad copies emphasizes the need to test various ad lengths to further enhance paid search success. For example, product-specific keywords providing additional information in a shortened ad copy are advantageous, whereas retailer-specific keywords benefit from being enhanced by an extended ad copy. When considering more specific search terms, an information cue is well suited to aid customers' search process and advertisers can make use of the specific informational needs of customers to craft optimized ad copies. Furthermore, for product-specific keywords marketers can leverage the deviating user behavior in response to ad copy design to maximize either the traffic on a website or conversion rates within a given budget. Our findings also have theoretical implications. To our knowledge we are the first to test the well-established information cue concept in the context of paid search and are able to provide the first empirical evidence on how user behavior is affected by information cues. Furthermore, observing behavioral differences in response to ad copy design highlights the need for researchers to assess user behavior on the basis of keyword characteristics and to consider clicks and conversions jointly. Our field experiment has, however, several limitations. First, the external validity of the experiment is inherently low due to its specific context (furniture retail) and conversion goal (lottery participation). Second, as we devised a specific target mechanism, our claims are restricted to the most prominently positioned ads directly below the search. One potential avenue for future research is to test our findings in other research environments. Beyond that, further research could assess the deviating behavior in more depth to shed light on the question of which patterns affect the observed user behavior. Previous scholars concluded that keyword characteristics (e.g., [15]) as well as the ad position (e.g., [7]) can be used to differentiate users by their intentions and therefore potential behavior. Our experimental results suggest that information needs can also be leveraged in an ad copy to influence user behavior. Detecting additional needs of customers, which could be incorporated in ad copy design, would allow advertisers to further improve the success of paid search. 


\section{References}

[1] http://www.emarketer.com/Article/Google-Will-Take55-of-Search-Ad-Dollars-Globally-2015/1012294.

[2] Rutz, O. and R. Bucklin, "Paid Search Advertising", in Advanced Database Marketing: Innovative Methodologies and Applications for Managing Customer Relationships. 2013.

[3] Desai, P.S., W. Shin, and R. Staelin, "The Company That You Keep: When to Buy a Competitor's Keyword", Marketing Science, 33(4), 2014, pp. 485-508.

[4] Lu, X. and X. Zhao, "Differential Effects of Keyword Selection in Search Engine Advertising on Direct and Indirect Sales", Journal of Management Information Systems, 30(4), 2014, pp. 299-326.

[5] Agarwal, A., K. Hosanagar, and M. Smith, "Location, location, location: An Analysis of Profitability of Position in Online Advertising Markets", Journal of Marketing Research, 48 (6)), 2011, pp. 1057-1073.

[6] Rutz, O. and M. Trusov, "Zooming In on Paid Search Ads - A Consumer-Level Model Calibrated on Aggregated Data”, Marketing Science, 30(5), 2011, pp. 789-800.

[7] Animesh, A., S. Viswanathan, and R. Agarwal, "Competing "Creatively" in Sponsored Search Markets: The Effect of Rank, Differentiation Strategy, and Competition on Performance", Information Systems Research, 22(1), 2011, pp. 153-169.

[8] Atkinson, G., C. Driesener, and D. Corkindale, "Search Engine Advertisement Design Effects on Click-Through Rates", Journal of Interactive Advertising, 14(1), 2014, pp. 24-30.

[9] Yoo, C.Y., "Unconscious processing of web advertising: Effects on implicit memory, attitude toward the brand, and consideration set", Journal of Interactive Marketing, 22(2), 2008, pp. 2-16.

[10] Eisend, M. and F. Tarrahi, "The Effectiveness of Advertising: A Meta-Meta-Analysis of Advertising Inputs and Outcomes", Journal of Advertising, 2016, pp. 1-13.

[11] Sudhir, K., "Editorial-The Exploration-Exploitation Tradeoff and Efficiency in Knowledge Production", Marketing Science, 35(1), 2016, pp. 1-9.

[12] Abernethy, A.M. and G.R. Franke, "The Information Content of Advertising: A Meta-Analysis", Journal of Advertising, 25(2), 1996, pp. 1-17.

[13] Jansen, B.J., K. Sobel, and M. Zhang, "The Brand Effect of Key Phrases and Advertisements in Sponsored Search", International Journal of Electronic Commerce, 16(1), 2011, pp. 77-106.

[14] Rutz, O. and R.E. Bucklin, "From Generic to Branded: A Model of Spillover in Paid Search Advertising”, Journal of Marketing Research, 48(1), 2011, pp. 87-102.
[15] Nottorf, F. and B. Funk, "A cross-industry analysis of the spillover effect in paid search advertising", Electronic Markets, 23(3), 2013, pp. 205-216.

[16] Jansen, B.J., Z. Liu, and Z. Simon, "The Effect of Ad Rank on the Performance of Keyword Advertising Campaigns", Journal of the American Society for Information Science \& Technology, 64(10), 2013, pp. 2115-2132.

[17] Narayanan, S. and K. Kalyanam, "Position Effects in Search Advertising and their Moderators: A Regression Discontinuity Approach", Marketing Science, 34(3), 2015, pp. 388-407.

[18] Turnbull, D. and L.F. Bright, "Advertising academia with sponsored search: an exploratory study examining the effectiveness of Google AdWords at the local and global level", International Journal of Electronic Business, 6(2), 2008, pp. 149-171.

[19] Haans, H., N. Raassens, and R. van Hout, "Search engine advertisements: The impact of advertising statements on click-through and conversion rates", Marketing Letters, 24(2), Jun, 2013, pp. 151-163.

[20] Yoo, C., "Interplay of message framing, keyword insertion and levels of product involvement in clickthrough of keyword search ads", International Journal of Advertising, 30(3), 2011, pp. 399-424.

[21] Ghose, A. and S. Yang, "An Empirical Analysis of Search Engine Advertising: Sponsored Search in Electronic Markets", Management Science, 55(10), 2009, pp. 16051622.

[22] Blake, T., C. Nosko, and S. Tadelis, "Consumer Heterogeneity and Paid Search Effectiveness: A LargeScale Field Experiment", Econometrica, 83(1), 2015, pp. 155-174.

[23] Resnik, A. and B.L. Stern, "An Analysis of Information Content in Television Advertising", Journal of Marketing, 41(1), 1977, p. 50.

[24] Bandiera, O., I. Barankay, and I. Rasul, "Field experiments with Firms", The Journal of Economic Perspectives, 25(3), 2011, pp. 63-82.

[25] Wooldridge, J.M., Introductory Econometrics: A Modern Approach, Cengage Learning, 2015.

[26] Davis, M.J., "Contrast coding in multiple regression analysis: Strengths, weaknesses, and utility of popular coding structures", Journal of Data Science, 8(1), 2010, p. 61 .

[27] Hosmer, D.W., S. Lemeshow, and R.X. Sturdivant, Applied logistic regression, Wiley, Hoboken, New Jersey, 2013. 